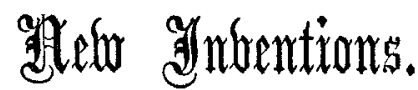

\section{RICHMOND'S PREPUCE DILATOR,}

FOR THE TREATMENT OF PHIMOSIS WITHOUT OPERATION.

THE only method of treating phimosis, in common practice, is by operation. There are, however, a great many patients suffering from this malady who absolutely refuse to undergo any operation for its relief. Numbers of cases are constantly presenting themselves of men considerably advanced in years who have never been able to get their foreskins back, and have consequently suffered continually from discharges attributable solely to the irritation attendant on this condition. Yet many such patients will rather pass their lives with the inconvenience and risk which this state of things in. volves than submit to the knife. There can, however, be only one other possible means of treating phimosis, and that is by stretching the prepuce. But this method appears to be very seldom put into practice, for when it is tried it generally results in failure. I can see no reason, however, why the skin and mucous membrane surrounding the glans penis should not be as freely dilatable as in other parts of the body. The reason of the failure, I take it, is simply that no proper instrument has been invented for the purpose. Extemporised instruments, such as dressing forceps, aneurysm needles, or blunted hooks, are painful and inadequate dilators. An instrument proper for the purpose should (1) possess blades which could be introduced separately ;
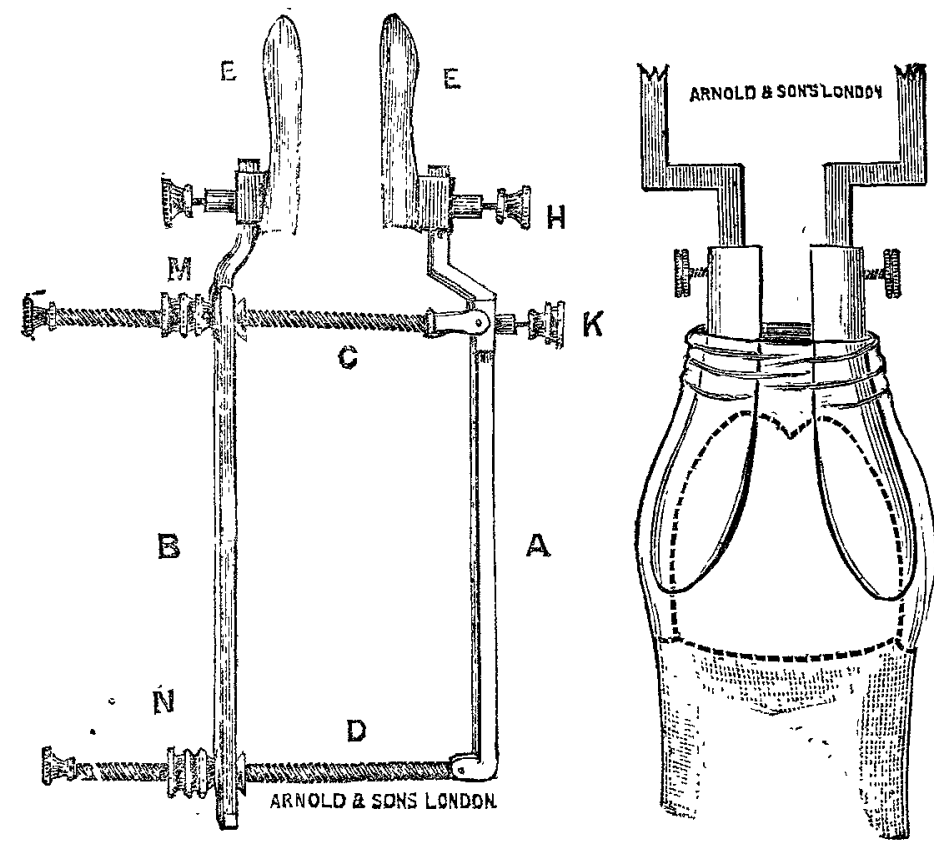

(2) the blades must be of suitable size and shape to suit the case ; and (3) it should be possible to open them parallel to one another or at any angle. The instrument which I have devised for this purpose consists of two rods, A B, connected together by means of two long screws, C D. At one extremity they are bent inwards and fixed to the blades, $\mathbf{E}$. These blades can be removed and may be of any size and shape. The rod, $\mathrm{B}$, is of a tuning. fork shape with the screw-nut, $M$, sliding in the groove between the two branches of the fork. Through the nut, $M$, is passed the long screw, $\mathrm{C}$, the end of which is received into a cup working on a hinge joint attached to the cylinder, $\mathrm{K}$, which slides along the bar, $A$. The screw end may be detached from the socket by pressing a little spring. The blades are passed separately down between the foreskin and glans. Very small blades are used at first, and they are of course previously oiled to facilitate their passage. They are then attached to the rods, which are united by fixing the end of the screw, $c$, into the cup-joint, $k$ The other serew rod, which is fixed only to the bar A by a joint, can be pulled over into the groove of $B$. Gradual extension can then be applied by turning the nuts $M$ and $N$. Since there is a joint at $K$ the blades may be opened parallel to one another, or at any angle, and in fact the relative position of the blades may be altered in any direction. The idea is not to stretch the foreskin forcibly, and at one sitting, but to dilate it gradually in the same manner as a stricture of the urethra is dilated by repeatedly passing a catheter. If the instrument be used once or twice a week for about ten minutes at a time, the foreskin will in most cases go back in a month or six weeks. The larger blades are used to thoroughly stretch the tissues and complete the treatment. The foreskin may thus be dilated to any reasonable extent, and will after a time easily roll back over the corona. The instruments are made by Messrs. Arnold and Sons.

St. Bartholomew's Hospital. W. STEPHENSON RICHMOND,

\section{A NEW FORM OF SUTURE.}

I BEG to submit to the notice of the profession a form of suture which in my opinion would be useful, and might in certain cases and in certain situations supersede witl advantage the ordinary means of approximating the edges of wounds. I am not aware that such a contrivance has. been used before, although the age of the thread suture and the absence of recent attempts to modify its principles of fixation would seem to indicate that it has reached the stage when modification is unnecessary and impossible. Nevertheless, the suture is objectionable in ways which will immediately suggest themselves to anyone who reflects for an instant on its application. 1 . It fails to approximate the walls of a wound in a desirable manner, only too often. bringing into contact the limited superficial portions of the tissues corresponding to where the threads are inserted, and leaving the deep parts unapproximated. 2. There is a cir. cular constriction, which frequently leads to ulceration and

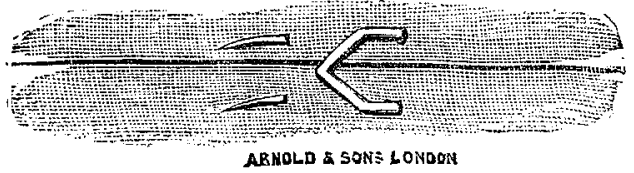

strangulation of the tissues enclosed within it, and thus to uselessness of the suture; while this defect is not at all times caused by a too tight application, but is indirectly owing to the smallness of the body which bears the strain of the tissues. 3. The suture acts as a foreign body in the wound, and causes those conditions which are known to prevent early union. These not being imaginary objections, but based on experience, I wish to suggest the following form of suture as fulfilling indications not met by the ordinary interrupted suture, and being at the same time easy of appli. cation. These sutures may be very readily introduced by a torsion forceps, which is made to grasp the $\mathbf{V}$-shaped bend, while the fingers of the left hand approximate the edges of the wound; after which, if the wound is not thoroughly closed, the wire may be clamped at the bend and the points brought closer together, with or without being held by a thread, or a piece of cork fastened on them. A piece of folded lint may then be applied under the bend to afford support to the wound. The sutures may be introduced either in the long axis of the wound, which is preferable; or across it, when a foreign body would of course be present. These sutures may be had of various thicknesses, sizes, and curves, with lancet points. They are made of silver, with hardened points, by Messrs. Arnold, of Smithfield.

Finsbury Park. $\quad$ Late Res. Med. Officer, Gt. Northern Hosp.

\section{A NEW TRACHEOTOMY TUBE.}

THOUGH gum elastic has, I believe, been used for tracheotomy tubes, hitherto all attempts have been failures. For the tube I now bring before the profession I cannot of course promise a success, but on theoretical grounds, as well as having received approval when a friendly criticism has been asked from distinguished members of the profession, I am induced to publish the results of my endeavours. I believe that of all tubes now in use, Mr. Durham's lobster tail, and the indiarubber tube of Mr. Morrant Baker have the most general popularity, the aluminium, the other silver, celluloid, vulcanite, \&c, being found inferior in one or other respect. For the lobster tail, durability, the rectangular curve, its method of introduction, and its movable shield give it special advantages, but it is very costly, complicated, heavy, and prone to produce ulceration and irritation. The indiarubber tube is light, 
soft, and consequently unlikely to irritate or ulcerate, and cheap; but its thickness, especially if on a webbing, its tendency to rot, collapse, and fall to pieces if not on a webbing, render it very unsafe, while it cannot be used from the beginning. In the gum-elastic tube I have sought to achieve all the virtues, while reducing to a minimum the disadvantages, of the other tubes. Messrs. Baker, of 243 , \#igh Holborn, have successfully made some under my direction. They are constructed of the thinnest material that can be made on a webbing (the shield and tube can be made in one piece), are very light, simple, and compressible when warm, but to a degree far short of collapsing, thus enabling them readily to accommodate themselves to the shape of the trachea and its movements, while their webbing framework will keep them from rotting and falling to pieces. They are very cheap, and as no mould is required as for indiarubber tubes, any modification of shape can be adopted according to the fancy of the surgeon. Those I have had made are rectangular, the tracheal end slightly incurved, with a small shield having lateral processes, varnished both inside and outside, and, provided due care be taken with their preparation and keeping, will, I believe, be always found clean and not sticky. I have

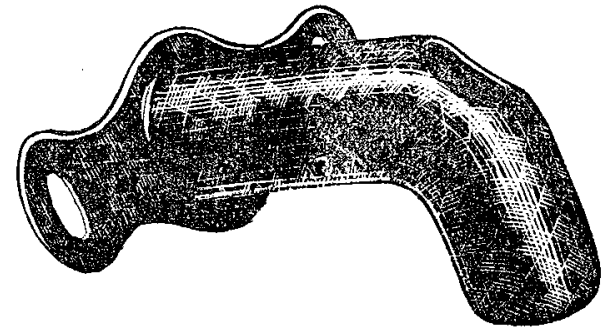

tried some other shapes, but I think that the one shown in the engraving, and just described, will be found the most useful. The engraving shows the tube a little tilted to one side. Those who have tied catheters in the bladder will know how much the best the gum-elastic catheter is for the purpose, and I may say it was that fact that first sug gested to me the use of gum elastic for a tracheotomy tube. Finally, as regards its use. When desired, it can be used immediately in conjunction with a lobster-tail inner tube, the latter to be left off as soon as convenient. And though this may increase its bulkiness and weight, yet it will not do so to such a degree as to impair its utility. But believing as I do that Mr. G. Bird's dilator is the best instrument in general for the first few days, especially in croup and diphtheria, its use would then be limited to those cases in which a tube has to be worn for a long time-e.g., after injuries of the larynx and other parts of that region, tumours, some inflammatory diseases, and during and after some operations upon the tongue and jaws, when tracheotomy is deemed advisable. Messrs. Baker are preparing tubes in different sizes, so as to make sets.

A. Rea Edwards, M.R.C.S., L.R.C.P.

Late House-Surgeon King's College Hospital.

\section{THE ANTIDOTE BAG}

Mr. Martindale, of New Cavendish-street, was the first to adopt a suggestion to produce a bag fitted with every remedy and appliance likely to be needed in the treatment of a case of poisoning. A notice of this really useful innovation appeared in these columns three years ago, and since that time other similar bags have been devised. Mr. Martindale has further improved upon his by omitting some articles, as the stomach-pump, enema, catheter, \&c., which are always at hand, and has thus not only rendered the bag more portable, but has been enabled to supply it at a greatly reduced cost. This smaller bag contains the following antidotes, which are labeled with directions for their use-viz., dialysed iron, syrup of chloral, chloroform, aromatic spirit of ammonia, spirit of chloroform, oil of turpentine, acetic acid, tincture of digitalis, nitrite of amyl capsules, sulphate of zinc, ipecacuanha, bromide of potassium, calcined maguesia, tannin, and a hypodermic case with syringe and solutions of acetate of morphia, apomorphia, nitrate of pilocarpine, sulphate of atropia, and nitrate of strychnine. The bag is supplied with a copy of Dr. Murrell's "What to Do in Cases of Poisoning."

\section{MICRO-ORGANISMS OF YELLOW FEVER.}

IT will be remembered that Dr. Domingos Freire is the author of several communications founded on investigations directed to prove that yellow fever is a contagious disease which owns a micro-organism as its proximate cause. A few weeks ago (The LANCET, July 29th, p. 29) we published an abstract of some experiments by Messrs. Mozley and Harrison, which went to prove that none of the conclusions at which Dr. Freire had arrived were correct. The latest phase of this discussion is a communication sent to us by Dr. Freire himself, and we propose to give here a résumé of his latest arguments and observations.

$\mathrm{He}$ thinks that the divergence in results is to be attributed to the widely different conditions under which their experiments were carried out. In the first place, Messrs. Mozley and Harrison injected into the animals liquids obtained by cultivating the earth taken from the graves of persons dead of yellow fever, whilst Dr. Freire employed the earth itself a few minutes after it had been merely diluted and mixed with pure water. It is contended that the particulate liquid injected by Dr. Freire was of great virulence, whereas on cultivation the virulence steadily diminishes. Further, the earth used by Dr. Freire came from individuals dead hardly a year, whilst the material employed by Messrs. Mozley and Harrison had lain three times as long. It is likely that the organisms would in that time have perished, the dead bodies having been reduced to little more than the condition of a skeleton; the more so as the bodies buried in coffins were separated from the earth which covered them by a layer at least of a corrosive substance (lime). In Dr. Freire's experiments the bodies were not surrounded with lime, and were not buried in coffins.

The two authors did obtain fatal results when material was taken immediately from the dead bodies; yet they were not inclined to look on the cause of death as due to yellow fever, but rather to a form of septicæmia. Dr. Freire, however, believes that in their experiments the micrococcus xanthogenicus was the agent in the production of the fatal disease, and he asks how it was, supposing the disease to have been septicæmia, that no bacteria were discovered in the blood. He perceives many lacunæ in the researches made by Messrs. Mozley and Harrison, and is curious to know whether they discovered in the earth employed the micrococcus which he has described as characteristic of yellow fever. He further argues that it is impossible for all guinea-pigs to manifest the symptoms of yellow fever, because species makes a difference, and may profoundly modify morbid processes. Moreover, accurate deseriptions of the conditions of all the viscera in guinea-pigs dead after inoculation with the peculiar earth are wanted, and these, with fresh evidence in support of his views, are about to be published by Dr. Freire, who has kindly sent us some of the proof-sheets in advance. In the first autopsy of a guinea-pig inoculated with some drops from a mixture of water and earth taken from the cemetery of Jurujuba, where individuals dead only of yellow fever are buried, the following lesions were noted :- Slight tint of jaundice over the skin of the animal; the brain of a decided grey colour; the lungs congested, and their surfaces studded with black areas; the beart dilated, and containing blackish blood in the ventricles; the liver swollen and blackish; the splcen also dark-coloured ; the stomach full of food, and its mucous membrane of a yellow colour ; the intestines of a y ellowish tint at certain parts and brownish in others; the kidneys swollen and congested; the urine albuminous; and the bladder full. A second necropsy was made, with similar results, on a guinea-pig, which had died after injection of some blood of another guinea-pig, which had lived in a confined atmosphere saturated with the spores of micrococcus xanthogenicus taken from the cemetery of Jurujuba. In all the post-mortem examinations Dr. Freire has found the same morbid changes, with yellow scattered granules and cryptococci of various sizes, shapes, and colours on microscopic examination of the blood. And here Dr. Freire ceases for the present, in the hope that Messrs. Mozley and Harrison will repeat the same experiments with all the necessary precautions. 